\title{
Configurations of Nanocubes Floating and Clustering on Liquid Surfaces
}

\author{
Tara A. Nitka ${ }^{1}$, Petr Král ${ }^{2}$, Lela Vuković*1 \\ ${ }^{1}$ Department of Chemistry and Biochemistry, University of Texas at El Paso, El Paso, Texas 79968, \\ United States \\ ${ }^{2}$ Departments of Chemistry, Physics, and Biopharmaceutical Sciences, University of Illinois at Chicago, \\ Chicago, Illinois 60607, United States
}

* Authors to whom all correspondence should be addressed: 1vukovic@utep.edu

\section{Electronic Supporting Information (ESI)}


Table S1. Summary of simulations performed.

\begin{tabular}{|c|c|c|c|c|}
\hline $\begin{array}{c}\text { nanoparticles in } \\
\text { the system }\end{array}$ & $\boldsymbol{\varepsilon}(\mathbf{k c a l} / \mathbf{m o l})$ & $\begin{array}{c}\text { core side } \\
\text { dimensions }(\mathbf{n m})\end{array}$ & time (ns) & $\begin{array}{c}\text { system size } \\
\text { (atoms) }\end{array}$ \\
\hline 1 cube & $\begin{array}{c}-0.1,-0.2,-0.25,-0.3, \\
-0.4,-0.5,-0.7\end{array}$ & 3.07 & 100 & 48,917 \\
\hline 2 cubes & 0.3 & 3.07 & 100 & 98,230 \\
\hline 2 cubes & 0.3 & 3.07 & 100 & 98,230 \\
\hline 3 cubes, $\mathrm{L}$ & 0.3 & 3.07 & 100 & 234,177 \\
\hline 3 cubes, line & 0.3 & 3.07 & 100 & 174,336 \\
\hline 3 cubes, $\mathrm{T}$ & 0.3 & 3.07 & 100 & 191,067 \\
\hline 4 cubes, $\mathrm{L}$ & 0.3 & 3.07 & 100 & 309,602 \\
\hline 4 cubes, line & 0.3 & 3.07 & 100 & 215,684 \\
\hline 4 cubes, staggered & 0.3 & 3.07 & 100 & 246,866 \\
\hline 4 cubes, square & 0.3 & 3.07 & 100 & 195,308 \\
\hline & & & & \\
\hline & ligand type & 5.1 & 100 & 196,289 \\
\hline 1 cube & $\left.-\mathrm{S}_{(\mathrm{CH}}\right)_{11} \mathrm{CH}_{3}$ & 5.1 & 100 & 197,144 \\
\hline 1 cube & $\mathrm{S}\left(\mathrm{CH}_{2}\right)_{11} \mathrm{OCH}_{3}$ & 5.1 & 100 & 197,150 \\
\hline 1 cube & $-{\mathrm{S}\left(\mathrm{CH}_{2}\right)_{12} \mathrm{OH}}$ & & & \\
\hline
\end{tabular}
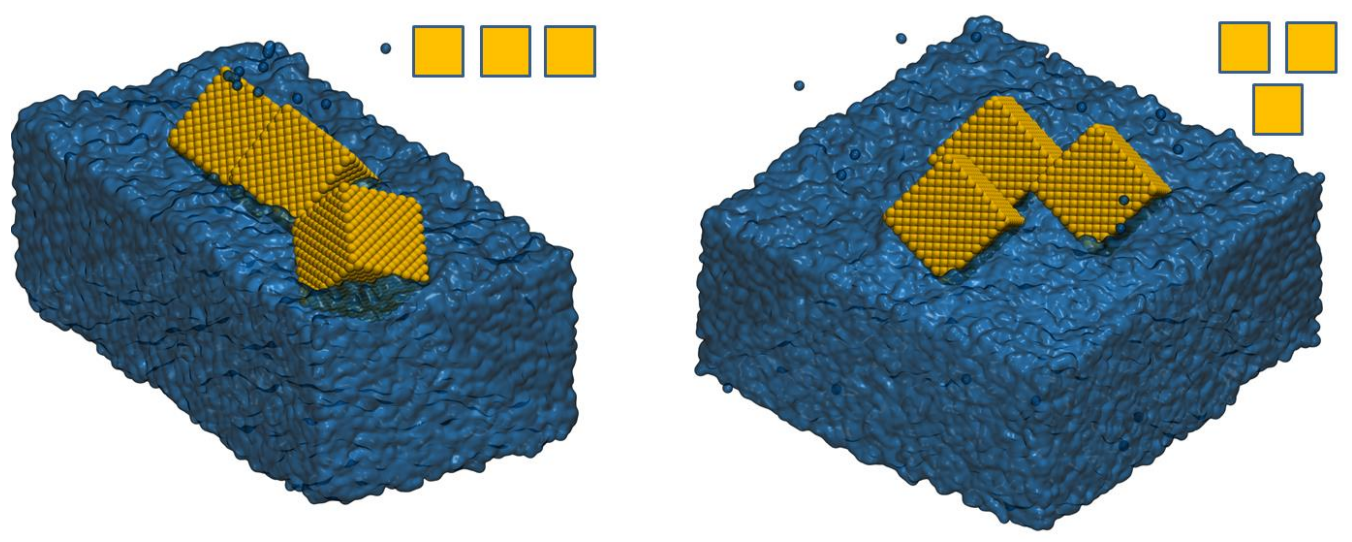

Figure S1. Self-assembly of three NCs $(\varepsilon=-0.3 \mathrm{kcal} / \mathrm{mol})$ in different initial arrangements (insets). In the initial state, the NCs have $55 \AA$ center-to-center distances. The snapshots are obtained after $100 \mathrm{~ns}$ of equilibration. 


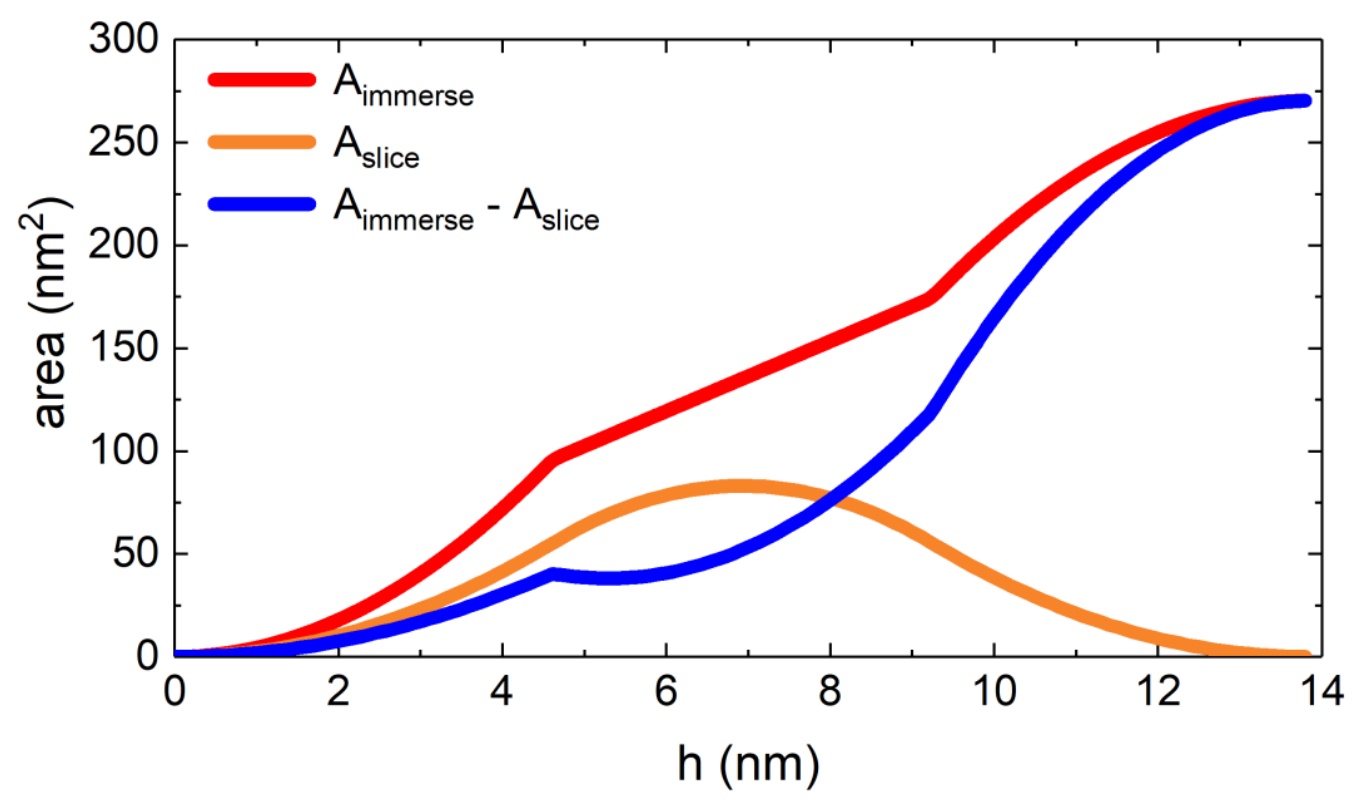

Figure S2. Contact area between an immersing tilted $\mathrm{NC}$ and the liquid $\left(\mathrm{A}_{\text {immerse }}\right)$, the area of the solvent replaced upon tilted $\mathrm{NC}$ immersion $\left(\mathrm{A}_{\text {slice}}\right)$, and the difference of the two areas as a function of immersion height $\mathrm{h}$, as derived in Equations 3-4.

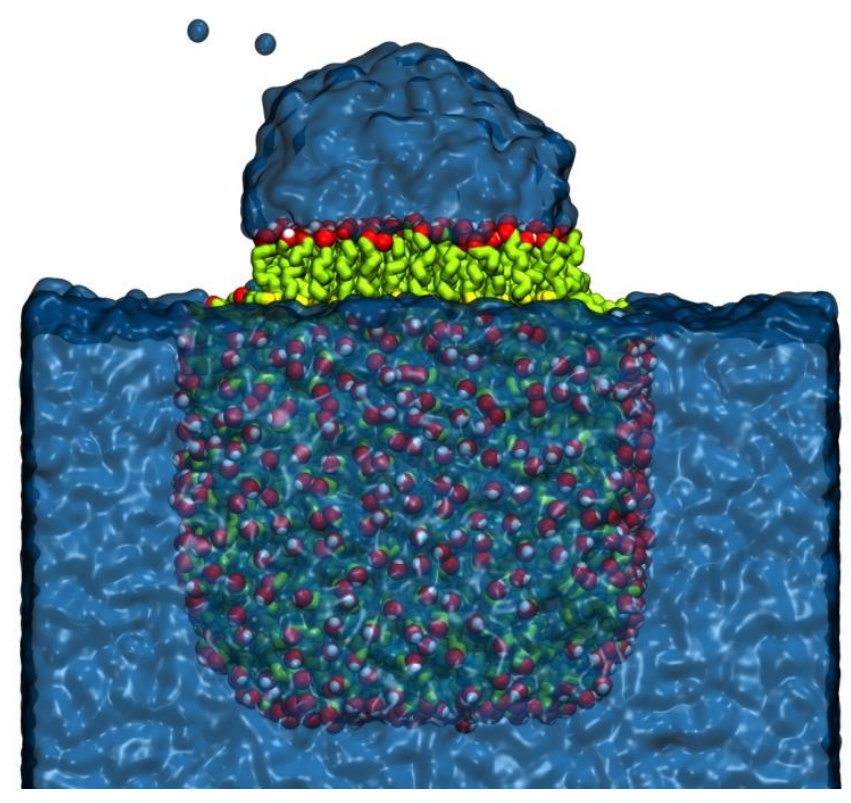

Figure S3. Ligands present on hydrophilic NCs can part at edges, leaving the hydrophobic alkyl groups of the ligand exposed, resulting in incomplete $\mathrm{NC}$ immersion. The figure above is a zoomed in version of Figure 2G. Carbon atoms of $-\left(\mathrm{CH}_{2}\right)_{12}$ groups are shown in green, oxygen atoms are shown in red and hydrogen atoms on $-\mathrm{OH}$ groups are shown in white. Hydrogen atoms on alkyl groups are not shown for clarity, but are present in the simulations. Water is shown as a transparent blue surface. 